\title{
Optimization of material flow using simulation
}

\author{
Oldřich Kodym ${ }^{1, *}, Z$ Zdeněk Čujan ${ }^{1}$, Michal Turek ${ }^{1}$, and Nikoleta Mikušová ${ }^{2}$ \\ ${ }^{1}$ College of Logistics, Palackeho 1381/25, 75002 Přerov, Czech Republic \\ ${ }^{2}$ TU Košice F BERG, Logistics Department, Park Komenského 14, 04001 Košice, Slovakia
}

\begin{abstract}
The strategic aim of all production enterprises is to achieve the highest possible profit, for which they use attributes of lean production that are related and support the reduction of production costs. Using of theoretical knowledge and realization of a detailed analysis of a material flow including mapping of individual production processes it is possible to obtain the necessary data sets identifying savings options by increasing of efficiency, including cost savings. Methods of modelling and simulation were used for the optimization of material flow.
\end{abstract}

\section{Introduction}

Material flow can be characterized as an organized flow of material in the production process with the required sequence determined by the technological procedure [1]. It is a summary of operations presented by material conveying, storage, packaging and weighing, technological manipulations and works directly related to the production process [2]. It also includes all kinds of auxiliary materials required for production process realization [3].

\section{Analysis of the current state}

The aim of the analysis is to find maximum factors which affect the value of the time demandingness of the orders processing. After mapping of different methods, a casual analysis was chosen as the most appropriate. This, like incidental analysis, deals with links among elements, phenomena, etc. Even though, the causal analysis deals only with causal relationships. It tries to discover the causes and their consequences. It is necessary to realize that each defined, causal-reason relationship is a certain simplification compared to reality.

Using a causal analysis, it is possible to create a modified model of the current reality (also known from the theory of restriction) and this can clearly illustrate the various factors and their causal-reason relationships that affect the value of total time demandingness of the process of orders processing in the production process. The basis for the creation of the modified model was a complex analysis of the production technology including interviews with managers and operators who supplemented some empirically determined values and facts [4-6].

Four basic areas were identified in the model of original reality with the aim to obtain the required data for material flow optimization:

- time analysis of layout from one operation to another,

- problem material flow and associated increased handling difficulty, 
- creation of queues in some workplaces,

- manual handwriting of forwarding bills by operators [7-9].

\section{A brief description of production technology}

The dashboard (Fig. 1) consists of three layers: a bottom plastic part with glass fibre, the top part forming a spatial formation with a non-developed surface, made by rotary sintering of powdered PVC and internal polyurethane fillings made on a robotized workplace by chemical reaction of two components, polyol and isocyanate (TDI). All three layers form a single unit (a sandwich) which is usually equipped with an airbag and it is one of the safety components of each car.

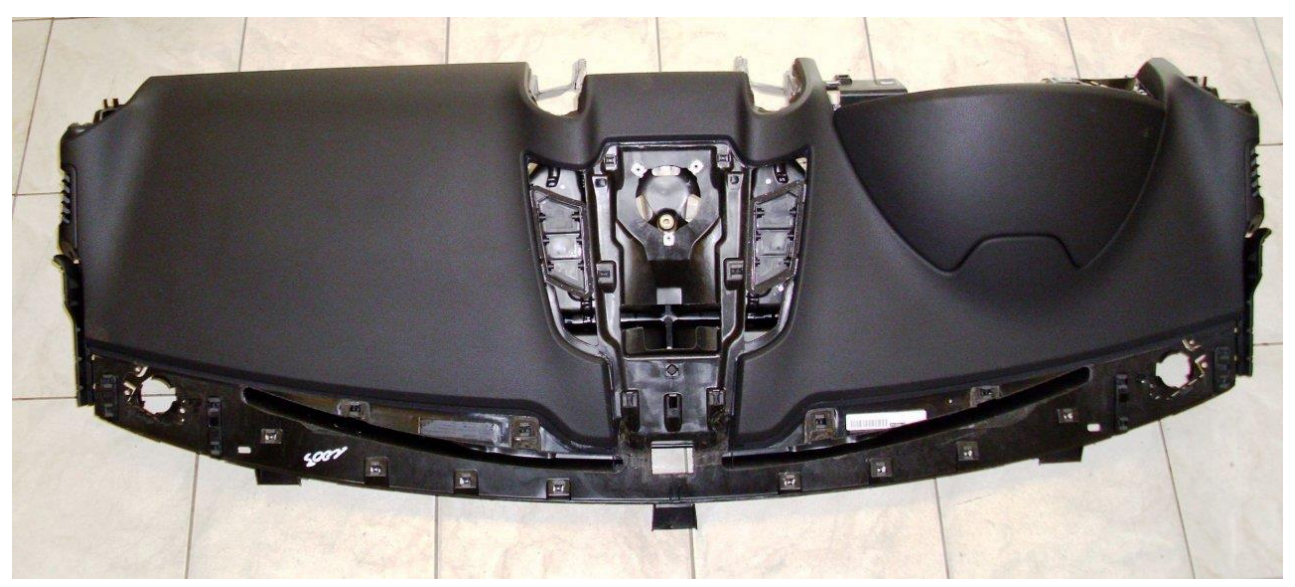

Fig. 1. Dashboard. Source: Autor

The bottom plastic part is made by the technology of injection from granulated PVC on the injection machine. The total production process, from mould closing to mould removal, is fully automatic. After making the mould and its cooling, it is followed by the manual processing of overflows, including the removal of the injection system.

The top part of the dash-board is produced on a special machine by the technology of rotary sintering of powder PVC at high temperature. The cylindrical-shaped closable support has a form in the interior of which cavity has a shape of a spatially non-developed surface of the dashboard including a surface design. A certain amount of PVC powder with the required colour is manually filled into the open mould, the mould is pneumatically closed and it is followed by heating of the interior to a temperature that is presented by the temperature of melting of the powered PVC. The mould on the support is rotated (the mould rotates around the longitudinal axis). The liquid PVC material equally fills the cavity in the mould by centrifugal force, then the interior is cooled by air. After this process, the cylindrical mould is opened and the hot final top part is removed from this part. The surface of the top part is provided with a design which must be checked under the UV lamp and the final part has a final shape by cutting off excess edges.

The middle polyurethane layer of the dashboard, which joins the lower support part with the top part which is made from PVC powder by rotary sintering in the required colour of the interior, is the result of chemical reaction of a polyol with isocyanate (TDI). A robot pours both of these components with a certain ratio to the open form with the determined trajectory. The robot works in fully automated mode. The actual chemical reaction 
(foaming) is realized in the closed top part of the form with lower plastic part fitted with pneumatic sucking disk.

In addition to the above-mentioned basic operations, with the need of realization, to produce a three-layer sandwich, which is the main part of all interior parts (all interior parts are produced with the same technology), the parts of the production process are other necessary operations, such as milling of circumferences of interior parts for the sizes according to the documentation, preassembly of safety components (airbags), insertion of clip anchors for electrical installation and own final assembly of the dashboard, which was realized on five separate workplaces on special assembling consoles by two workers before optimization.

\section{Process approach and measuring of time demandingness}

For production operations was realized chronometry with the aim to determine time demandingness of these activities including material handling. In order to be as accurate as possible, up to 50 measurements were made for each activity. This helps to eliminate accidental disturbing impacts. The obtained values for modelling and simulation were averaged.

Material flow with average time data:

1 - material input, supply $\left(\mathrm{t}_{1}=60 \mathrm{sec}, \mathrm{d}_{1}=15 \mathrm{~m}\right)$

2 - assembly: 5 workplaces $\left(\mathrm{t}_{2}=6300 \mathrm{sec}, 10 \mathrm{~m}\right)$

3 - output control $\left(\mathrm{t}_{3}=600 \mathrm{sec}, 4 \mathrm{~m}\right)$

4 - packing: 2 workplaces $\left(\mathrm{t}_{4}=252 \mathrm{sec}, 4 \mathrm{~m}\right)$

5 - delivery: 2 workplaces $\left(t_{5}=252 \mathrm{sec}, 10 \mathrm{~m}\right)$

One of the key problems arising from the realized causal analysis confirms the longdiscussed hypothesis, it was increased the volume of manual handling with interior parts in the place of assembly. This fact was in direct relation to the way of the realization of the assembly, which was realized manually in five separate workplaces.

Each workplace was equipped with special assembling stands and always two operators realized assembly of the dashboard (Table 1).

The layout (Fig. 2) of the workplace and the way of assembly were the basic parameters for optimizing the assembly of the dashboard.

Table 1. Average time data of operations.

\begin{tabular}{|c|c|c|c|c|c|c|}
\hline \multicolumn{7}{|c|}{ Assembly of the dashboard on the stands } \\
\hline Activity & Operation & Distance & Sec. & Min. & $\begin{array}{l}\text { Number of } \\
\text { workers }\end{array}$ & Note \\
\hline Supply & Fork-lift truck & $15 \mathrm{~m}$ & 60 & 1 & 3 & \multirow{10}{*}{$\begin{array}{l}\text { D } \\
0 \\
0 \\
0 \\
0 \\
0\end{array}$} \\
\hline Assembly & Manual workplace 1 & \multirow{5}{*}{$10 \mathrm{~m}$} & 6300 & 105 & 2 & \\
\hline & Manual workplace 2 & & 6280 & 104,7 & 2 & \\
\hline & Manual workplace 3 & & 6320 & 105,33 & 2 & \\
\hline & Manual workplace 4 & & 6300 & 105 & 2 & \\
\hline & Manual workplace 5 & & 6320 & 105,33 & 2 & \\
\hline Control & visual & $4 \mathrm{~m}$ & 600 & 10 & 2 & \\
\hline Package & manual & $4 \mathrm{~m}$ & 240 & 4 & 4 & \\
\hline Delivery & Fork-lift truck & $10 \mathrm{~m}$ & 240 & 4 & 2 & \\
\hline Total & & & 32660 & 544,33 & 21 & \\
\hline
\end{tabular}




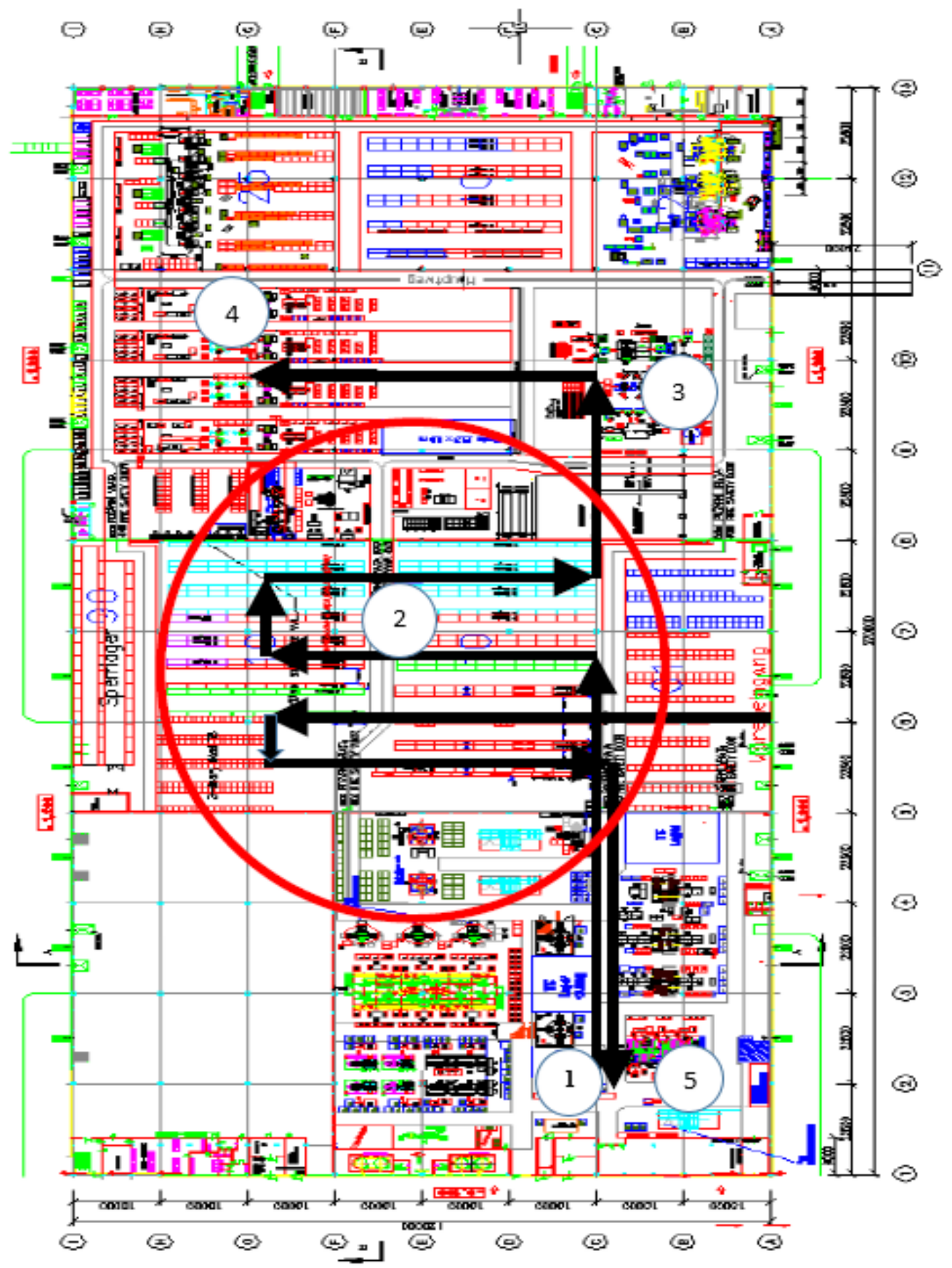

Fig. 2. The model proposed work in 3D. Source: Autor 


\section{Design of new layout of assembly workplace}

On the base of the realized analysis of the production procedure, we started to arrange the assembly workplace to the cell. The concept of lean production prefers the type of the "U-line" because it has the most advantages:

- activities of operators and material supply do not cross,

- the beginning and the end of the line are at the main communication,

- short distances among operators (distance among the first and the last is minimized),

- no barriers in the communication among operators.

The original discrete method of assembly was supplanted by the continuous assembly on the open line of the type "U", which allows a continuous way of assembly (Fig. 3). The proposed method required a change in the way of assembly line supplying (Table 2) and also in the new layout of the workplace and the use of modelling and simulation had a favourable effect on the overall layout of the production hall. The result of the proposed solution was a new layout of assembly workplaces and related change in the way of supplying the assembly line. The continuous assembly on the open line with individual operations and managed production tact enabled to optimize the number of operators by the maintenance of the original performance.

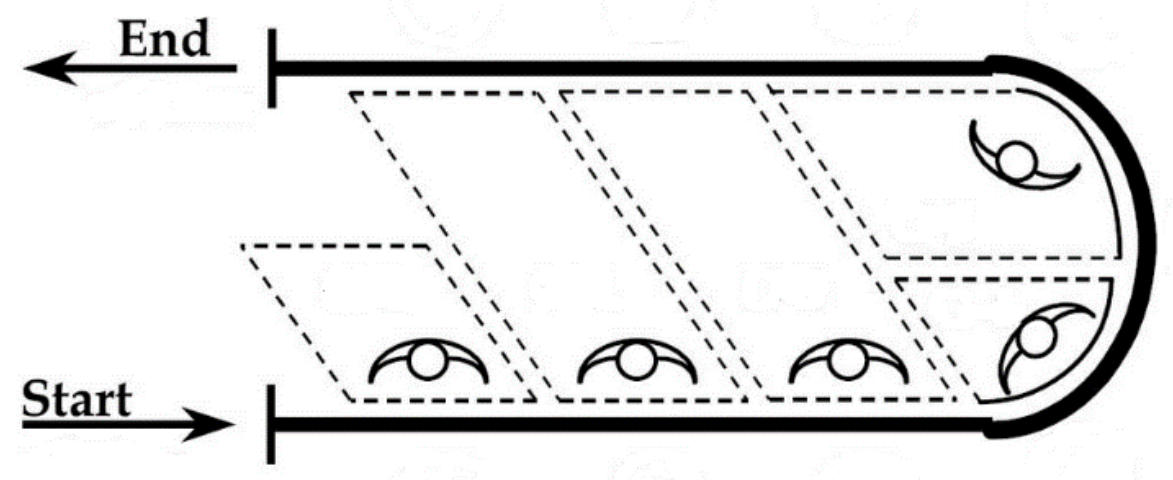

Fig. 3. Assembly line of the type "U" after optimization. Source: Autor

Table 2. Average time data of operations in the line.

\begin{tabular}{|c|c|c|c|c|c|c|}
\hline \multicolumn{7}{|c|}{ Assembly of the dashboard on the open line with controlled tact } \\
\hline Activity & Operation & Distance & Sek. & Min. & Number of workers & Note \\
\hline Supply & Fork-lift truck & $8 \mathrm{~m}$ & 60 & 1 & 2 & \multirow{10}{*}{$\begin{array}{l}\text { D } \\
\text { : } \\
0 \\
0 \\
\text { : }\end{array}$} \\
\hline \multirow[t]{5}{*}{ Assembly } & Manual workplace 1 & \multirow{5}{*}{$6 \mathrm{~m}$} & 60 & 1 & 1 & \\
\hline & Manual workplace 2 & & 60 & 1 & 1 & \\
\hline & Manual workplace 3 & & 60 & 1 & 1 & \\
\hline & Manual workplace 4 & & 60 & 1 & 1 & \\
\hline & Manual workplace 5 & & 60 & 1 & 1 & \\
\hline Control & visual & $4 \mathrm{~m}$ & 600 & 10 & 2 & \\
\hline Package & manual & $4 \mathrm{~m}$ & 240 & 4 & 4 & \\
\hline Delivery & Fork-lift truck & $6 \mathrm{~m}$ & 240 & 4 & 2 & \\
\hline Total & & & 1440 & 24 & 15 & \\
\hline
\end{tabular}




\section{Customer tact:}

Customer tact means the interval in which the customer obtains the final product or service. The calculation is based on (1) :

- available working hours (week, month, etc.),

- customer needs in pieces $(\mathrm{m}, \mathrm{kg}$, etc.) for the monitored period.

$$
\begin{gathered}
T_{z}=\frac{t_{m}}{i}=\frac{(5 \times 60) x 7}{10}=210 \mathrm{pc} / \mathrm{shift} \\
\frac{d x}{d t}=a_{1} x
\end{gathered}
$$

- where $\quad t_{m}-$ customer needs in pieces

I - available working hours

\section{An optimal number of operators:}

Calculation of the theoretical needs of operators provides orientation information for the line balancing (Table 3). The optimal number of operators is given by the ratio of the production line and customer tact (2) :

$$
O_{\text {opt }}=\frac{t_{v}}{T_{z}}=\frac{60}{12}=5 \quad \text { operators } T_{z}=\frac{t_{m}}{i}=\frac{(5 \times 60) \times 7}{10}=210 \mathrm{pc} / \mathrm{shift}
$$

$$
\frac{d x}{d t}=a_{1} x
$$

- where $\quad t_{p}-$ ratio of the production

$\mathrm{T}_{\mathrm{z}}$ - customer tact

In order to meet the customer's requirements, we assume 5 operators according to the calculation. We can choose between two options by installing the assembly line:

- application of "chasing", when all operators proceed in equable spacing from the first to the last operation in the line; the great advantage of this system is the fact that it allows simple control of the line speed using the same standard procedure.

- The second option is the possibility of redistributing of operations among operators so that all workers are equally busy, i.e. for the speed of the line, it is needed to prepare standards for operators, with the scheme when the operator starts the work and when hands the work to another operator.

Effectivity of the assembly line is verified by the value of the Index of balance, this is calculated as the ratio of the sum of the times of manual activities and maximum time of operator multiplied by the number of operators (3) :

$$
O_{\text {opt }}=\frac{t_{v}}{T_{z}}=\frac{60}{12}=5 \quad \text { operators }
$$

$T_{z}=\frac{t_{m}}{i}=\frac{(5 \times 60) x 7}{10}=210 \mathrm{pc} / \mathrm{shift}$

$$
\frac{d x}{d t}=a_{1} x
$$

- where $\quad t_{c} \quad-$ the ratio of the sum of the times of manual activities

$t_{\max }-$ maximum time of operator multiplied by the number of operators 
Table 3. Values for the line with controlled tact.

\begin{tabular}{|c|c|c|c|c|c|c|}
\hline \multicolumn{7}{|c|}{ Assembly of the dashboard on the open line with controlled tact } \\
\hline Activity & Operation & Distance & Sec. & Min. & $\begin{array}{l}\text { Number } \\
\text { of } \\
\text { workers }\end{array}$ & Note \\
\hline Supply & Fork-lift truck & $8 \mathrm{~m}$ & 60 & 1 & 2 & \multirow{10}{*}{$\begin{array}{l}\text { D } \\
0 \\
0 \\
0 \\
0 \\
0\end{array}$} \\
\hline \multirow[t]{5}{*}{ Assembly } & Manual workplace 1 & \multirow{5}{*}{$6 \mathrm{~m}$} & 60 & 1 & 1 & \\
\hline & Manual workplace 2 & & 60 & 1 & 1 & \\
\hline & Manual workplace 3 & & 60 & 1 & 1 & \\
\hline & Manual workplace 4 & & 60 & 1 & 1 & \\
\hline & Manual workplace 5 & & 60 & 1 & 1 & \\
\hline Control & visual & $4 \mathrm{~m}$ & 600 & 10 & 2 & \\
\hline Package & manual & $4 \mathrm{~m}$ & 240 & 4 & 4 & \\
\hline Delivery & Fork-lift truck & $6 \mathrm{~m}$ & 240 & 4 & 2 & \\
\hline Total & & $28 \mathrm{~m}$ & 1440 & 24 & 15 & \\
\hline
\end{tabular}

Taking into account the future development that is related to the realization of the proposed layout of the workplace of assembly and the change of material flow, a new layout of the production hall was developed (Fig. 4).

For the new layout of workplaces, we used the analysis of material flow and consequently the method of CRAFT, the principle of which is to minimize the transport performance, which is given by (4):

$$
\begin{aligned}
& \quad O_{o p t}=\frac{t_{v}}{T_{z}}=\frac{60}{12}=5 \quad \text { operators } \quad T_{z}=\frac{t_{m}}{i}=\frac{(5 \times 60) x 7}{10}=210 \mathrm{pc} / \mathrm{shift} \\
& \frac{d x}{d t}=a_{1} x
\end{aligned}
$$

-where $\quad \mathrm{Q}-$ transported amount [pieces]

1 - distance $[\mathrm{m}]$

$\mathrm{t}$ - time [s]

For the economically advantageous realization of the solution, the effect must be obtained by the new layout (Fig.4) of elements, exceed costs for their layout. Mathematically, the method of optimization of the positioning of logistics elements, can be described as $n$ number of elements, $\mathrm{v}_{\mathrm{ij}}$ number of loading units (material, product, etc.), moving between the element $\mathrm{i}$ and $\mathrm{j}, \mathrm{u}_{\mathrm{ij}}$ costs for movement of the loading unit per unit of distance between the element $\mathrm{i}$ and $\mathrm{j}[\mathrm{K} c \mathrm{c}]$, lij distance between the element $\mathrm{i}$ and $\mathrm{j}[\mathrm{m}$, $\mathrm{km}, . .$.$] ,$

Total costs of material flow among elements $i$ and $j$ are calculated from the equation (5):

$$
O_{o p t}=\frac{t_{v}}{T_{z}}=\frac{60}{12}=5 \quad \text { operators } \quad T_{Z}=\frac{t_{m}}{i}=\frac{(5 \times 60) \times 7}{10}=210 \mathrm{pc} / \mathrm{shift}
$$

$$
\frac{d x}{d t}=a_{1} x
$$

-where $\quad c_{i j}-$ costs for material flow between the elements $i$ and $j$ per unit of distance

$\mathrm{l}_{\mathrm{ij}} \quad-$ the distance between the elements $\mathrm{i}$ and $\mathrm{j}$

The calculation of the minimum of these functions is realized sequentially by iterations (Table 4). 
Table 4. Traffic system values.

\begin{tabular}{|l|l|l|l|l|l|}
\hline & $\begin{array}{l}\text { New } \\
\text { layout }\end{array}$ & $\begin{array}{l}\text { Iteration } \\
\text { I }\end{array}$ & $\begin{array}{l}\text { Iteration } \\
\text { II }\end{array}$ & $\begin{array}{l}\text { Iteration } \\
\text { III }\end{array}$ & $\begin{array}{l}\text { Iteration } \\
\text { IV }\end{array}$ \\
\hline Total transportation output [ks.m/s] & 3,9 & 2,6 & 2,6 & 2,6 & 3,9 \\
\hline Total transportation course $[\mathrm{m}]$ & 28 & 43 & 38 & 33 & 28 \\
\hline Time demandingness [s] & 1440 & 3266 & 2874 & 2514 & 1440 \\
\hline
\end{tabular}

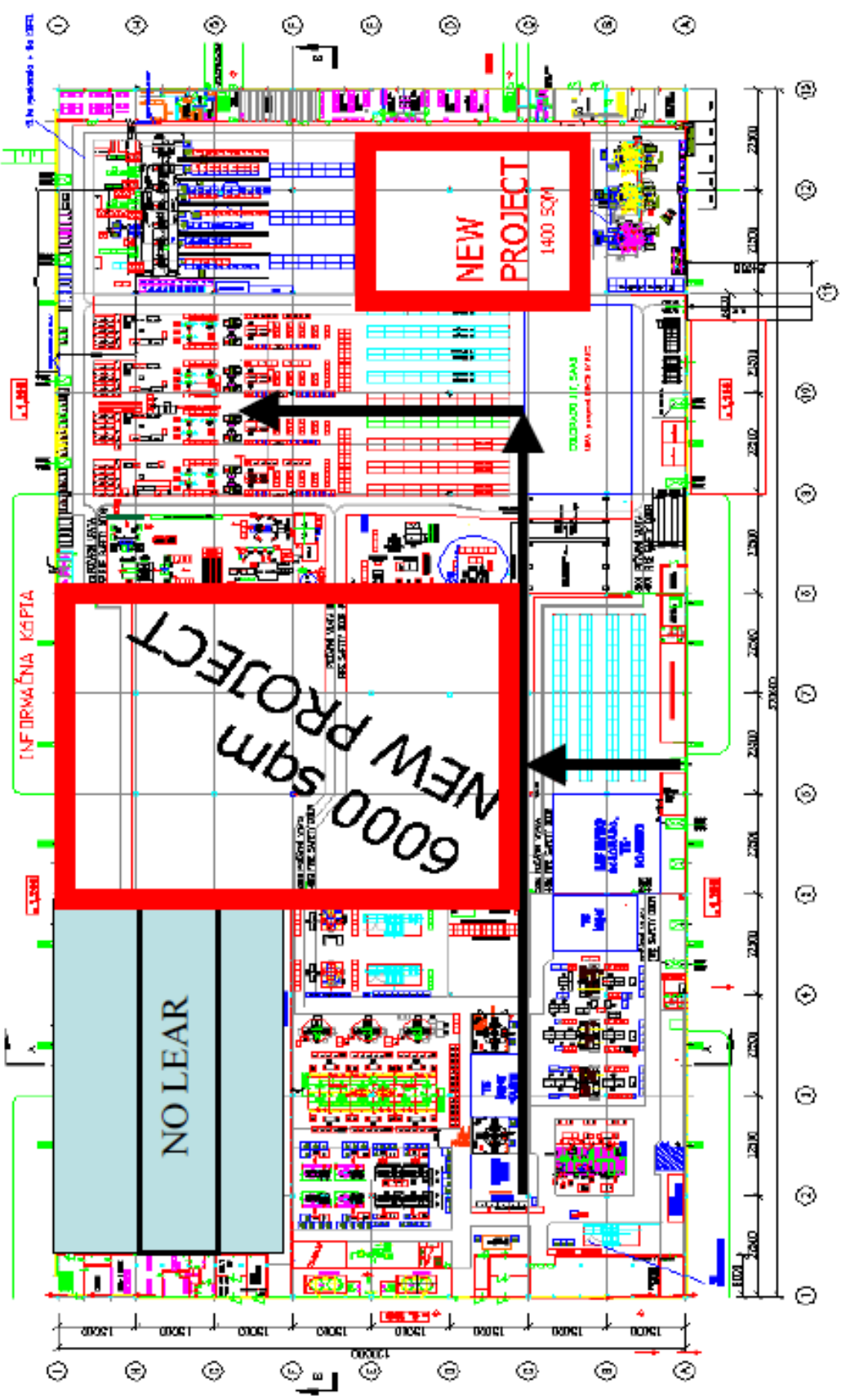

Fig. 4. The layout of the production hall after optimization using simulation. Source: Autor 


\section{Modelling and simulation}

Modelling is an experimental process, in which physical or abstract model is associated with the examined object (real object, machine, etc.) - the modelled system. Modelling allows to imitate and monitor properties of processes and predict their behaviour. Simulation is mainly focused on a finding of optimal layout of a system, identification and elimination of bottlenecks, dimensioning and placing of production and warehouse capacities, etc. An important demand for the model is the possibility of experimenting with the model in real time. The experiment explores the properties of the model and its interaction with the environment. The process of experimentation with the model is called simulation. With the help of simulation experiments, it is possible to look for alternatives and suitable parameters of the projected equipment, or repair or extend knowledge about the examined system. Input parameters for the model are in Fig. 5. Modelling and simulation were realized in the simulation program Witness simulations, and its final variant is presented in this paper (Fig. 6).
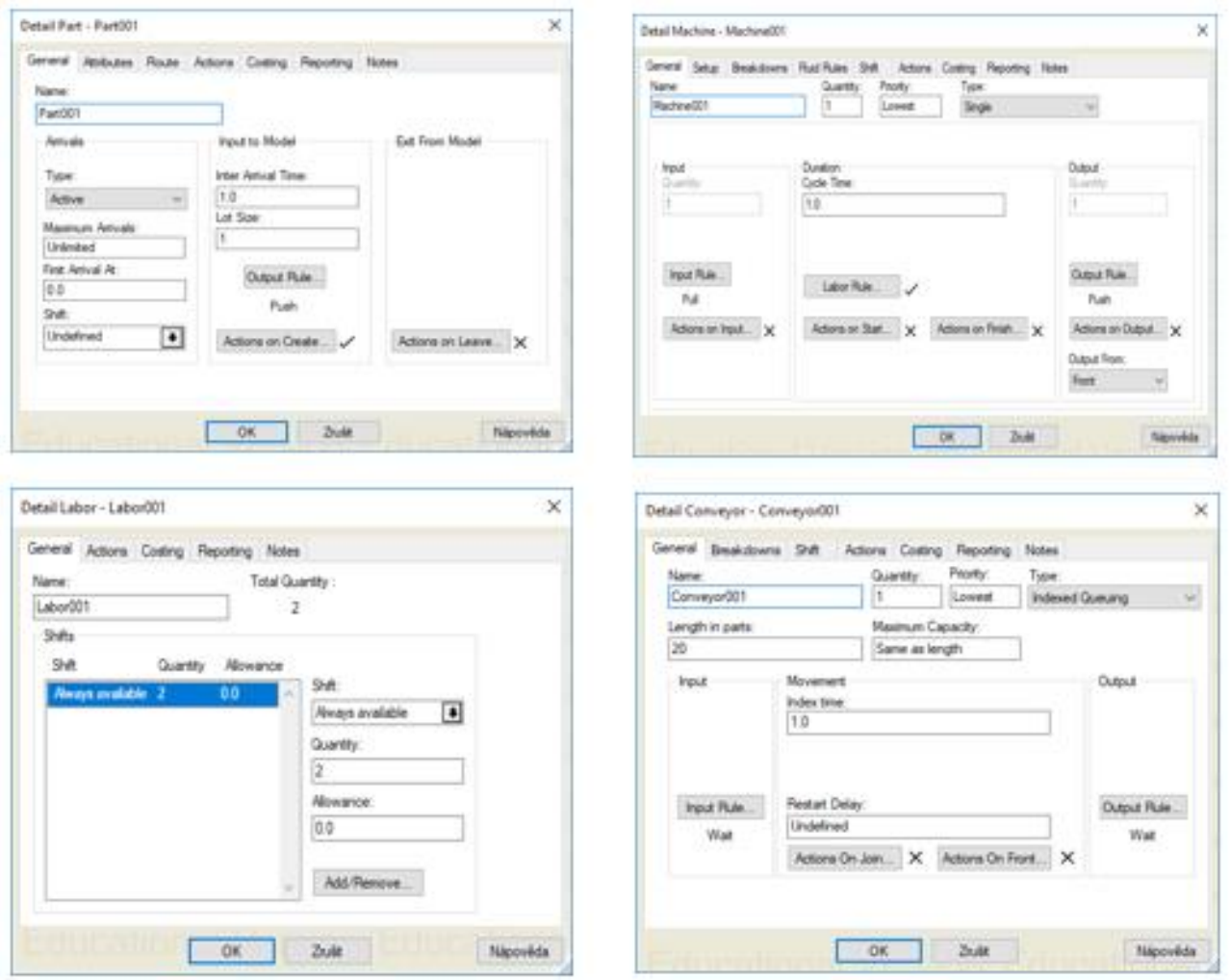

Fig. 5. Input parameters for the model. Source: Autor

\section{Conclusion}

The paper is an example of analysis and subsequent optimization of material flow. The original study aimed at optimizing of material flows achieved not only to the reorganization of the layout of workplaces, but it was an impulse for the new layout of assembling workplace including implementation of automatic identification using barcoding. It is evident that the use of system thinking and process approach, together with 
the application of knowledge from logistics, can bring significant benefits not only in the economic field but also in the improvement of the working environment, satisfaction of employees and thereby also competitiveness of the enterprise.

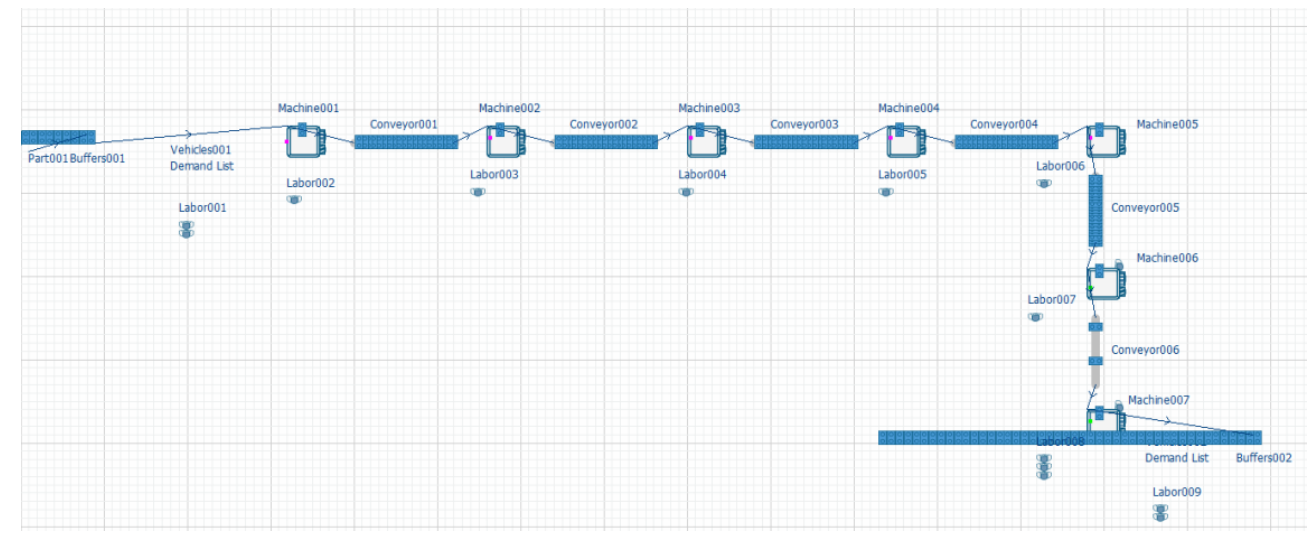

Fig. 6. Model of optimized material flow in the simulation program Witness. Source: Autor

The present paper is a part of research grant projects VEGA 1/0063/16, VEGA 1/0403/18, KEGA 018TUKE-4/2016.

\section{References}

1. F. Azadivar, W. Sim. C. Proc. 31, 8 (1999)

2. http://www.humusoft.cz/pub/witness/syst9903/sim_rp.htm

3. Z. Cujan, Production technology logistics (VSLG, Prerov, 2013)

4. M. Hamer, J. Champy Reengineering (Management Press, Prague, 2000)

5. V. Preclik, Industrial logistics (CVUT, Praha, 2006)

6. http://www.cvis.cz/hlavni.php?stranka=novinky

7. http://www.bartech.cz/kontakty/bartech_auta.pdf

8. http://www.simulace.cz/media/art/modsim.pdf

9. D. Sabadka, V. Molnar, G. Fedorko, T. Jachowicz, Adv. In Sc. And Technol. - Res. Journal 11(4), 175-182 (2017) 